\title{
Construyendo realidades: usos de bullying en discursos chilenos
}

\section{Constructing Realities: Bullying Usages in Chilean Discourses}

\author{
Rodrigo Bassaletti-Contreras ${ }^{1}$ \\ Universitat Autònoma de Barcelona, España
}

(Rec: mayo 2013 - Acep: junio 2013)

\begin{abstract}
Resumen
El artículo da cuenta de una investigación exploratoria sobre los usos que se da en Chile al anglicismo bullying. Para ello se revisa su evolución desde los primeros estudios en los países nórdicos, hasta el tratamiento del tema en el contexto chileno.

El enfoque de este trabajo es socioconstruccionista y promueve a su vez la consideración de las características del contexto socio-histórico-cultural en la producción de conocimiento con una intención postcolonial. Para revisar las construcciones en torno al tema, se seleccionaron videos chilenos en la plataforma virtual YouTube, utilizando como metodología el análisis del discurso y la descripción densa.

En los resultados se observan dos acepciones para bullying: (i)para referirse a cualquier tipo de agresión y (ii) como homólogo de abuso entre escolares. Ante ello, se da cuenta de la discrepancia con las definiciones propuestas desde el mundo académico general y aquellas utilizadas en el medio local en las investigaciones, intervenciones, políticas públicas y medios de comunicación masivos chilenos.

Palabras clave: bullying, violencia escolar, socioconstruccionismo, Chile, análisis de discurso.
\end{abstract}

\begin{abstract}
The article reports an exploratory research on the uses given in Chile to the Anglicism bullying. In order to do so, its evolution is reviewed from the early studies in the Nordic countries, to the treatment of the topic in the Chilean context.

The focus of this work is based on socioconstructionism and in turn promotes the consideration of the characteristics of the socio-cultural and historical context of knowledge production with a postcolonial intention. To review the constructions on the subject, we selected Chilean videos at the YouTube virtual platform, using as methodology discourse analysis and dense description.

In results can be observed two meanings of bullying: (i) to refer to any kind of aggression and (ii) as a homologous of abuse among schoolchildren. In response, it is realized the discrepancy with the proposed definitions from general academia and those used in the local environment in investigations, interventions, public policy and mass media in Chile.
\end{abstract}

Key words: bullying, school violence, socioconstructivism, Chile, discourse analysis.

\footnotetext{
1 Correspondencia a: Universitat Autònoma de Barcelona. Facultad de Psicología, Campus UAB, Edificio B, 08193, Cerdanyola del Vallès (Bellaterra). E -mail: rbassaletti@gmail.com.
} 


\section{Introducción}

"Todas las cosas son palabras del idioma. En que Alguien o Algo, noche y día, Escribe esa infinita algarabía Que es la historia del mundo".

(Jorge Luis Borges, 1998, p. 196)

El concepto de bullying surge en los países nórdicos (Noruega, Suecia y Finlandia) en los años setenta y posteriormente se extiende a otras regiones del mundo. En un contexto social como el de Chile, distintos autores locales prefieren hablar de "violencia escolar" al aplicar el término por sobre otros conceptos importados, mirada que coincide con las políticas e intervenciones desarrolladas en el tema. Pese a ello, es el anglicismo bullying el que se ha instalado en el país en la cotidianeidad de las personas, siendo utilizado en los medios de comunicación masivos y reproduciéndose a menudo en estudiantes, padres y madres para referirse a distintos tipos de conflictos o comportamientos de violencia escolar. Pero ¿qué se está diciendo al hablar de bullying?

A lo largo de esta investigación, se profundizará en la evolución de dicho concepto, su masificación en el contexto sociocultural chileno y en los usos que popularmente se le otorga para construir discursos asociados al tema.

\section{Una mirada socioconstruccionista del concepto bullying}

En general se plantea que para la comunidad científica bullying refiere a "una conducta agresiva sistemática y reiterada contra determinados niños y en una relación de desequilibrio de poder entre los agresores y sus víctimas" (Pepler, Rigby \& Smith, 2004 y Olweus, 1993, en Ortega, 2010, p. 130; Smith, Pepler \& Rigby, 2004; Garaigordobil \& Oñederra, 2010; Wolf \& Esteffan, 2008; Avilés, 2006; Sullivan, Cleary \& Sullivan, 2005). Esta definición hace énfasis en la inequidad de poder entre las partes y en el sometimiento de uno sobre otro (que por lo demás lo define como un tipo de violencia). Deja abierta la apertura para observar distintos tipos de bullying, tales como aquellos relacionados con las redes sociales (cyber bullying), o bien aquellos relacionados con el racismo, homofobia, género, e incluso los que se originan fuera del espacio escolar (como el bullying entre hermanos). Asimismo, permite hacer diferencias con respecto a otras situaciones también frecuentes en las escuelas, que pueden implicar comportamientos agresivos pero que no serían bullying, tales como las interacciones bruscas, los juegos rudos, las disrupciones, indisciplina o los problemas de gestión de aula por parte del docente.

No obstante, pese a este consenso aparente, no hay acuerdo en relación a los matices socioculturales que la problemática adopta en cada región del mundo, ni claridad con respecto al término más adecuado para referirse a este fenómeno en cada territorio (Del Rey, Genevat y Ortega, 2002). De esta forma, queda en entredicho el referido 'consenso' de la comunidad científica, usando en algunos casos el término bullying de forma indistinta como 'acoso escolar' (Garaigordobil \& Oñederra, 2010) o incluso a 'violencia escolar' (Lecalennier, 2007). Por ello, llama aún más la atención cómo este concepto es utilizado en la cotidianeidad por personas que no están familiarizadas con la temática, especialmente teniendo en cuenta que el lenguaje da sentido a nuestro mundo, tiene efectos en cómo vivenciamos una situación, o, en términos socioconstruccionistas, que $\mathrm{el}$ lenguaje construye realidades. En efecto, el repertorio disponible de elementos lingüísticos o "repertorio interpretativo" (Potter \& Wetherell, 1987) está determinado por factores sociales, históricos y culturales, por lo cual resulta relevante considerar tales elementos a la hora de entender la difusión de este anglicismo.

Lo anterior destaca que cada forma de construir el mundo es parte de una tradición, con una historicidad particular (Ibáñez, 2001), que conlleva determinados valores y que a la vez descarta todo aquello que no está incluido en su propia cultura (Gergen \& Gergen, 2011). Esta tradición se manifiesta en el lenguaje, el cual realiza acciones y, con ello, modela determinadas realidades para las personas (Garay, Iñíguez \& Martínez, 2005). Teniendo esto en cuenta, ¿Cómo ha sido construido el concepto bullying en diversos contextos culturales?

\section{Evolución del constructo: desde los países nórdicos al resto del mundo}

Las primeras referencias relacionadas con el fenómeno datan de 1969, con el psiquiatra sueco Peter-Paul Heinemann quien lo denominó mobbing, entendiéndolo como la agresión de un grupo de alumnos contra uno de sus miembros que interrumpe las actividades ordinarias del colectivo (Garaigordobil \& Oñederra, 2010; Ortega, 2010). No obstante, su compatriota Dan Olweus, fue el primero en ocupar el término bullying, 
en una investigación realizada sobre la prevalencia del fenómeno en varones adolescentes de su país (19731978). Anatol Pikas, también sueco, escribió en 1975 el primer libro sobre la intervención del bullying, teniendo gran repercusión en los países nórdicos; a este, se sumaron las investigaciones de Kjerstil Lagerspetz en Finlandia en 1982 (Ortega, 2010). Noruega estaba especialmente sensibilizada a raíz de una ola continua de suicidios de jóvenes a causa de bullying, que motivó la realización de la primera campaña de prevención y del primer congreso sobre el tema en 1983. Si bien pocos investigadores estaban familiarizados con el fenómeno específico, su competencia teórica en torno a las conductas antisociales fue crucial para dar inicio a la investigación y a la intervención en este terreno (Ortega, 2010).

En estos inicios, Olweus demarcó el fenómeno usando la siguiente definición: "Un alumno sufre bullying cuando se encuentra expuesto, de forma reiterada y prolongada en el tiempo, a acciones negativas por parte de uno o varios otros alumnos" (Olweus, 1993 en Ortega, 2010). Desde entonces el constructo ha evolucionado, incluyendo las conductas intimidatorias de un individuo a otro y las formas de agresión verbal, social o gestual (y no sólo las físicas). Esta evolución, sin embargo, se complejiza al incorporar las variables socioculturales.

Garaigordobil \& Oñederra (2010) realizaron una revisión de los primeros estudios del fenómeno, en la que se observa cómo desde los países nórdicos (Suecia en 1973, Finlandia en 1982, Noruega en 1983), se extienden a otros países europeos (Irlanda, Reino Unido y España en 1989, Holanda en 1990, Alemania y Bélgica en 1993, Austria en 1996, Portugal e Italia en 1999). Según esta recopilación, en el resto de los continentes los estudios de prevalencia surgieron en Japón (en 1985), Estados Unidos (en 1988), Australia y Canadá (en 1991). En cuanto a Latinoamérica, los autores señalan investigaciones en Brasil, México, Nicaragua, Bolivia, Argentina, Costa Rica, todos sobre el año 2002 (Garaigordobil \& Oñederra, 2010). En sus conclusiones plantean que:

“(...) se constata la dificultad de realizar un análisis comparativo de la prevalencia, aunque sí se pueden observar tendencias y características generalizadas. Todos los estudios, sin excepción, evidencian la existencia del acoso escolar entre iguales, por lo que se puede concluir que es una realidad en todos los centros escolares del mundo". (Garaigordobil

\& Oñederra, 2010, pp. 181-182).

Ahora bien, otra cosa es coincidir con que el fenómeno estudiado es el mismo.

\section{Sobre la construcción del término bullying en el contexto latinoamericano}

En investigaciones desarrolladas en contextos no anglosajones, en general se recopila información sobre el fenómeno adaptando el concepto a vocablos utilizados en el idioma de los países, empleando en algunos casos el término original ${ }^{2}$. En las lenguas romances no hay un término único para traducir bullying, siendo utilizados términos aproximativos como la prepotenza en Italia, fazer mal en Portugal, y el meterse con en España. Otros términos utilizados por autores españoles son "matonismo", "intimidación" y "maltrato entre iguales" (Avilés, 2006).

En el idioma castellano, los estudios utilizan una gran variedad de nombres que configuran un abanico de posibilidades. Al respecto, la investigadora española Rosario Ortega señala:

"En la lengua española, contamos con muchos vocablos que refieren comportamientos diferentes pero similares, y que podrían incluirse dentro de la categoría bullying, como por ejemplo: abuso, maltrato, meterse con, violencia, prepotencia, etc." (Ortega, 2010, p. 66).

Lo anterior se evidencia en las distintas investigaciones realizadas en la América Latina hispanoparlante, incorporando tales términos en iniciativas de prevención, de intervención u otros proyectos referidos a la violencia escolar. La proliferación de estudios sobre el tema, ha sido impulsada por hechos violentos graves protagonizados por estudiantes, los que han tenido repercusión pública.

Un aspecto a considerar, en el caso de los países del cono sur de América, especialmente Chile, Argentina y Uruguay, es que la violencia escolar se problematiza a mediados de los noventa, tras la caída de las dictaduras militares de estas naciones, en un contexto donde el tema de la violencia en general, empieza a ser materia

\footnotetext{
2 La palabra bullying deriva de la inglesa bully, que literalmente significa “matón” o "bravucón” (Garaigordobil \& Oñederra, 2010).
} 
de análisis y preocupación a nivel social, mediático y académico (Madriaza, 2007). Este contexto histórico post-dictatorial, marca el sentido de las políticas públicas y las lógicas de intervención, buscando fomentar los valores democráticos. A ello se sumaría un progresivo desarrollo de valores individualistas a nivel cultural, en desmedro de los colectivistastradicionales, más la existencia de una enorme desigualdad a nivel social, económico y educacional entre la población más pudiente y los más desposeídos (Madriaza, 2007).

\section{El concepto bullying en Chile}

En la investigación. En Chile, al igual que en los contextos hispanoparlantes antes señalados, no existe una traducción literal del fenómeno. Las violencias asimétricas se han considerado desde los inicios de la investigación en el país, pero han sido interpretadas con el prisma de modelos importados desde la violencia intrafamiliar y el maltrato infantil, e inmediatamente trasladados al contexto educativo, siendo que la violencia escolar también comprende agresiones simétricas como las peleas individuales y grupales (Madriaza, 2007). Por esta razón, se plantea que las explicaciones construidas se vuelven más complejas cuando la agresión es bidireccional, transformándose en un fenómeno de violencia más amplio (Sprague, Tijmes \& Varela, 2009).

En torno a las conceptualizaciones del fenómeno, se listan una serie de terminologías tales como: acoso escolar, victimización, hostigamiento, maltrato entre pares, matonaje, agresión entre pares, interacciones agresivas e intimidación entre pares (Sprague, Tijmes $\&$ Varela, 2007). Esta variabilidad conceptual se refleja desde las primeras investigaciones, las que se desarrollanen Chile especialmente desde el cambio de milenio y poniendo énfasis en la violencia física existente, en el sentido de la violenciay los tipos de violencia escolar (Madriaza, 2007). En ellas se observó victimización en torno a agresiones verbales y físicas, amenazas y/o exclusión, y robo con amenaza, por lo cual se infiere que el concepto de violencia escolar a la base incluye también agresiones distintas a las físicas, como las psicológicas y/o las de tipo social como la exclusión.

Las variaciones en la terminología utilizada ha sido el factor decisivo para que distintos investigadores utilicen en genérico "violencia escolar" de manera indistinta a bullying, explicitando que usan ambos términos considerando la discusión teórica al respecto y que el fenómeno como tal es importado y pertenece a otras claves culturales (Sprague, Tijmes \& Varela, 2009; Lecalennier, 2007; Madriaza, 2007).

En los proyectos y programas de intervención. Madriaza (2007) clasifica los programas de intervención chilenos en tres posiciones: (i) en Educación para la Paz y la No Violencia, orientada al desarrollo de la sana convivencia, de una cultura de la paz y la educación en valores (por ejemplo: programa Valoras UC, los proyectos de Educar Chile); (ii) en Mediación y Resolución Alternativa de Conflictos, orientada a la entrega específica de herramientas a estudiantes y/o docentes para enfrentar los conflictos a través del diálogo y el acuerdo (por ejemplo: proyecto de Resolución Pacífica de Conflictos y Mediación de la comuna de La Florida, Mediación Escolar de municipalidades como Temuco o Coquimbo, Programa de Apoyo a la Cohesión Social UE-Chile en Punta Arenas, programa de Prevención del Acoso Escolar desarrollado por el Centro de Mediación de Iquique); y (iii) en Gestión Escolar, las cuales plantean una intervención universal a nivel de la organización escolar y especialmente, una guía para los equipos líderes de cada comunidad educativa (por ejemplo: Paz Educa de Fundación Paz Ciudadana, desarrollado en Puente Alto, Recoleta y Huechuraba).

A partir de la revisión realizada, se observa que la mayoría de las estrategias se enfocan en la prevención de la violencia sin detenerse explícitamente en el bullying, aunque se evidencian casos donde se utiliza el concepto indistintamente a violencia escolar para dar cuenta de los objetivos de intervención.

En la Ley y las políticas públicas. El surgimiento de intervenciones sobre violencia escolar y bullying cabe entenderlo dentro del proceso de re-democratización del país luego de la Dictadura Militar (1973- 1990). En este escenario, según Madriaza (2007), la violencia emerge como tema de preocupación pública, razón por la que las intervenciones en la al respecto se guían por los principios democráticos señalados por el Ministerio de Educación [MINEDUC], los cuales apuntan a valores ciudadanos democráticos y de convivencia pacífica: "respeto por la diversidad, participación activa en la comunidad, colaboración, autonomía y solidaridad" (Madriaza, 2007).

En el ámbito legal, el 17 de septiembre de 2011 entró en vigencia la Ley 20.536 Sobre Violencia Escolar, que modifica la Ley $N^{\circ} 20.370$ General de Educación (MINEDUC, 2011). En ella, se especifican responsabilidades para los establecimientos educacionales en torno a la prevención de todo tipo de violencia escolar, la promoción de una buena convivencia en la 
comunidad educativa y las sanciones pertinentes en casos de violencia. Se aclara también el uso del concepto de "acoso escolar", a saber:

"[...] toda acción u omisión constitutiva de agresión u hostigamiento reiterado, realizada fuera o dentro del establecimiento educacional por estudiantes que, de forma individual o colectiva, atenten en contra de otro estudiante, valiéndose para ello de una situación de superioridad o de indefensión del estudiante afectado, que provoque en este último maltrato, humillación o fundado temor de verse expuesto a un mal de carácter grave, ya sea por medios tecnológicos o cualquier otro medio, tomando en cuenta su edad y condición". (MINEDUC, 2011, Artículo 16 B).

De la anterior definición se puede establecer entonces una relación entre acoso escolar con lo que la literatura plantea como fenómeno bullying, en tanto enfatiza la violencia asimétrica. Se enfatiza, también, la idea de "buena convivencia escolar" entendida como la coexistencia armónica de los miembros de la comunidad educativa que permite el adecuado cumplimiento de los objetivos educativos (MINEDUC, 2011).

En los medios de comunicación masivos. En 1996 aparece por primera vez el concepto violencia escolar en los medios de comunicación, asociándose a hechos graves de violencia como homicidios o intentos frustrados de homicidios (Madriaza, 2007).Sin embargo, no es hasta 2006 cuando la problemática cambia conceptualmente hacia el anglicismo bullying, enmarcado en una fuerte difusión mediática que lo instala como preocupación pública a raíz de casos como el de una estudiante en Antofagasta, zona norte del país, quien se suicida tras un hostigamiento reiterado por parte de sus compañeros (Madriaza, 2007; Sprague, Tijmes \& Varela, 2009; Wolfe \& Estefan, 2008).

En este sentido, se marca una evolución en los medios de comunicación desde un énfasis en los hechos de violencia física graves (como las agresiones con armas) hacia formas de agresión psicológica o social (como el hostigamiento), pero que tienen efectos físicos graves en quienes los sufren. Madriaza señala al respecto (2007), que es el concepto bullying el que acapara portadas y noticias, restringiendo a este fenómeno el discurso en torno a la violencia escolar. Así considera que "en los medios la agresión en la escuela es unifactorializada quedando definida unívocamente en una dicotomía agresor/víctima, donde priman fundamentalmente y tienen más tribuna las explicaciones psicológicas e individualistas" (Madriaza, 2007, p. 136).

Esta explicación individualista es la que hace pensar y relacionar la masificación del concepto bullying con el individualismo desarrollado en la sociedad chilena actual.

\section{No sólo una cuestión semántica: justificación desde una perspectiva socioconstruccionista y poscolonial}

¿Qué repercusiones tiene el uso que se haga del término bullying? Lo que las personas entiendan por bullying estará dando cuenta de cómo se ha construido y construye a través del tiempo este fenómeno, pero también plantea la inquietud en torno a por qué se fortalece este concepto en contraposición a otros que incluso son los que se manejan a nivel teórico y en las intervenciones públicas (como 'violencia escolar', por ejemplo). De esta manera, llama la atención el popular uso -y abuso- del término bullying.

La hipótesis que se plantea en esta investigación, es que existiría cierta relación entre los usos de este término con los aspectos socioculturales descritos en la sociedad chilena actual, esto es principalmente, una disonancia entre estos valores colectivistas que persiguen las políticas públicas y aquellos individualistas desarrollados por una sociedad de consumo como la que se ha implementado en Chile en los últimos 20 años. Paralelamente, se introducen en forma paulatina constructos producidos por la investigación científica de países "desarrollados", sin profundizar, sin embargo, en las características particulares del escenario nacional.

Este estudio busca reflexionar sobre ello y desde esta perspectiva, justifica una mirada poscolonialista en la investigación en torno al tema, enfatizando la historicidad del concepto y la necesidad de romper con la tradicional hegemonía de la tradición europea y estadounidense en la producción de conocimiento, profundizando en los significados propios que adopta el fenómeno estudiado en la sociedad chilena.

Las interrogantes que guían la investigación son: ¿cuáles son los usos que se le están dando al concepto bullying? ¿Cómo se masifica en Chile este concepto nacido en el mundo angloparlante? ¿Con qué contenidos se está vinculando el constructo? A partir de estas preguntas se estableció como objetivo general, identificar los usos que popularmente comprende el anglicismo bullying, reflexionando en torno a su 
evolución como constructo y su masificación en el contexto sociocultural chileno. Asimismo, se fijaron tres objetivos específicos:

i. Describir la evolución del concepto bullying en la comunidad científica, especificando su uso en el contexto sociocultural chileno.

ii. Señalar usos del término bullying en discursos chilenos.

iii. Plantearinferencias sobre la apropiación del anglicismo bullying en la sociedad chilena con respecto al contexto socio-histórico-cultural del país.

\section{Metodología}

Este trabajo se enmarca dentro de la investigación en espacios virtuales o e-research. Según Elisenda Ardèvol \& Gemma San Cornelio (2007), en sitios de alojamiento y distribución de imágenes como YouTube, se crea un espacio de interacción social, lo que equivale a un nuevo medio de comunicación de multitudes y que se presenta como espacios de apropiación de significados culturales relacionados con prácticas sociales tales como entretenimiento, trabajo, creación personal, contestación y resistencia política.

Al plantear la investigación desde esta perspectiva, los videos encontrados en YouTube son entendidos como documentos donde se concentran significados culturales en torno al término bullying, objeto de estudio de este trabajo. En este sentido, interesó buscar distintos videos subidos por chilenos y chilenas en torno al tema, donde se revisaron los usos dados a este anglicismo.

Los métodos de análisis utilizados devienen de la tradición lingüística: para analizar los contenidos verbales de los videos se trabajó con el análisis de discurso planteado por Jonathan Potter y Margaret Wetherell, consistente en identificación de funciones, variaciones, tropos y repertorios interpretativos, mientras que los contenidos visuales y auditivos se presentaron mediante descripción densa. Se escogieron estos métodos pues son coherentes con las preguntas formuladas, las que apuntan a develar aspectos referentes a las prácticas lingüísticas y sus relaciones con la construcción del fenómeno.

En cuanto al análisis del contenido verbal se optó por la definición de discurso de Iñíguez \& Antaki (1994, en Garay, Iñíguez \& Martínez, 2005), la cual señala que corresponde a un conjunto de prácticas lingüísticas que mantienen y promueven ciertas relaciones sociales, consistiendo el análisis de discurso, en estudiar cómo estas prácticas actúan en el presente manteniendo y promoviendo estas relaciones.
Para comprender el enfoque, es necesario definir sus conceptos relevantes. Como primer aspecto, el análisis de las funciones refiere al elemento pragmático del lenguaje, esto es, a lo que hace el discurso (explicar, justificar, afirmar, etc.). Como los hablantes proporcionan perspectivas cambiantes y variadas de sus mundos sociales, ellas pueden develarse a través de la variabilidad en el discurso y de las renuncias (disclaimer), mecanismo verbal diseñado para protegerse de atribuciones potencialmente nocivas (Potter \& Wetherell, 1988, en Gordo \& Linaza, 1996). Por ejemplo: "no soy clasista, pero los...". En este caso el receptor puede estar seguro que pese a que el hablante explicita que no realiza discriminación por clase social, la expresión que viene a continuación del "pero" será negativa en torno a una clase social determinada. Finalmente, se pueden encontrar una serie de metáforas, metonimias u otros tropos y figuras retóricas, las cuales también tienen determinadas funciones tales como exagerar una idea, atenuar el discurso, etc. (Potter \& Wetherell, 1988, en Gordo \& Linaza, 1996). Este análisis permite identificar un marco de regularidades o repertorio interpretativo, vale decir, una gama de unidades lingüísticas, relativamente vinculadas y consistentes, que conforman los elementos esenciales que los hablantes utilizan para construir versiones de las acciones, los procesos cognitivos y otros fenómenos (Potter \& Wetherell, 1988, en Gordo \& Linaza, 1996).

Por otro lado, los contenidos visuales y auditivos fueron presentados mediante descripción densa. Este concepto refiere a una descripción que accede a una jerarquía estratificada de estructuras significativas, en las cuales se producen, se perciben e interpretan los datos disponibles. En este sentido, la descripción densa corresponde a interpretaciones de los códigos establecidos, de los códigos culturales, y en este sentido, "la cultura es pública porque la significación lo es" (Geertz, 1992). De esta forma, si el investigador es parte de este contexto cultural, sus interpretaciones también darán cuenta de esta trama de significados.

\section{Diseño}

Procedimiento. Para la obtención de los datos, en primer lugar se abrió un diario de campo para registrar la investigación y monitorear el proceso de la misma. Su uso permitió revisar continuamente los criterios de selección del material a utilizar y elaborar reflexiones en torno a los contenidos de los videos y a las consideraciones éticas relacionadas con el trabajo de los datos. 
Luego se realizó la búsqueda de videos en YouTube con los descriptores bullying, Chile, tomando en consideración las 2 primeras páginas de resultados (la última búsqueda fue realizada el 05 de abril, 2012). Se filtró el material (40 videos) en función de dos criterios:

a. Usuario/a chileno/a

b. Que en su producción o edición no participasen instituciones o medios de comunicación (campañas, reportajes de prensa, documentales, conferencias de académicos). El factor "edición" es considerable, pues plantea interrogantes en cuanto a quién es el que efectivamente "está hablando" a través del video. Tampoco se consideraron los comentarios al video (de otros/as usuarios/as).
Se identificó el material seleccionado (9 videos), utilizando una tabla en donde se registró el título del video, su ubicación web, fecha en que fue cargado a la plataforma YouTube y otros aspectos que podrían ayudar en el análisis. Puede apreciarse una muestra del proceso en la Figura 1.

Los videos se dividieron en fragmentos y se separaron los contenidos verbales (escritos y orales), visuales y auditivos. La información se ordenó en una tabla de registro de datos audiovisuales (Tabla 1) y posteriormente, se releyeron todas las transcripciones, complementando y revisando las descripciones realizadas.

Posteriormente, se llevó el contenido verbal transcrito en las tablas de datos audiovisuales a una tabla

Figura 1.

Cuadro de identificación de videos seleccionados.

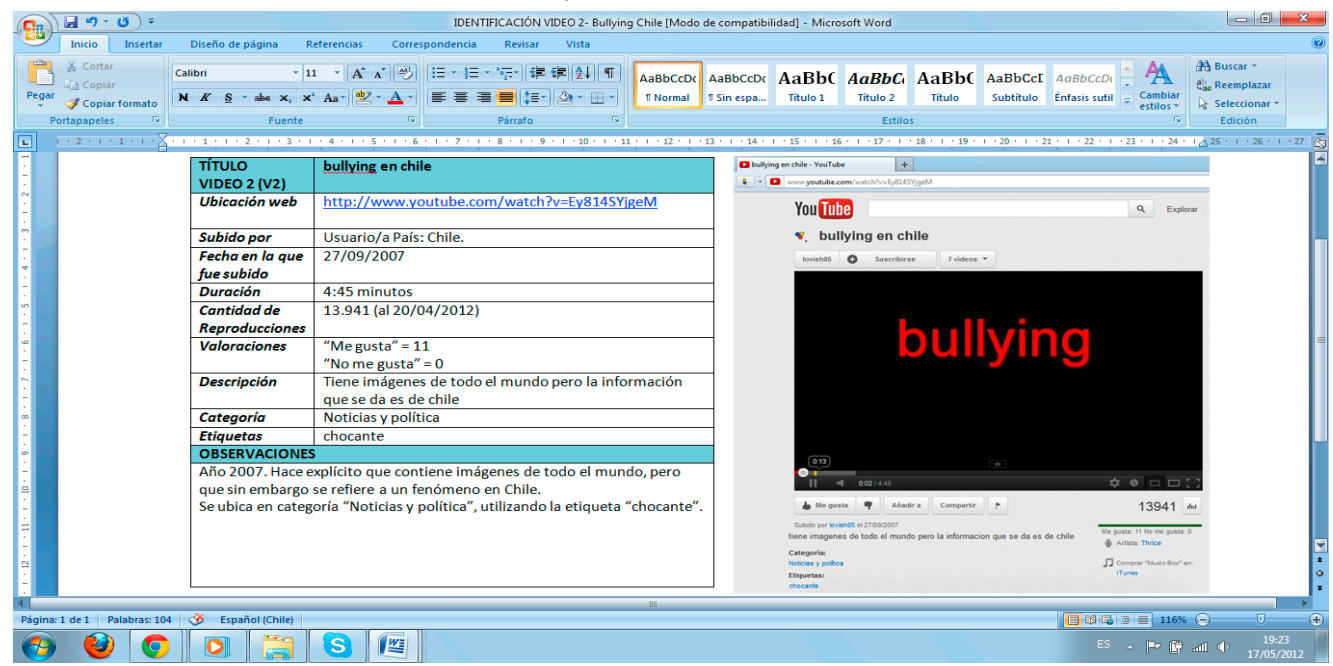

Tabla 1.

Datos audiovisuales.

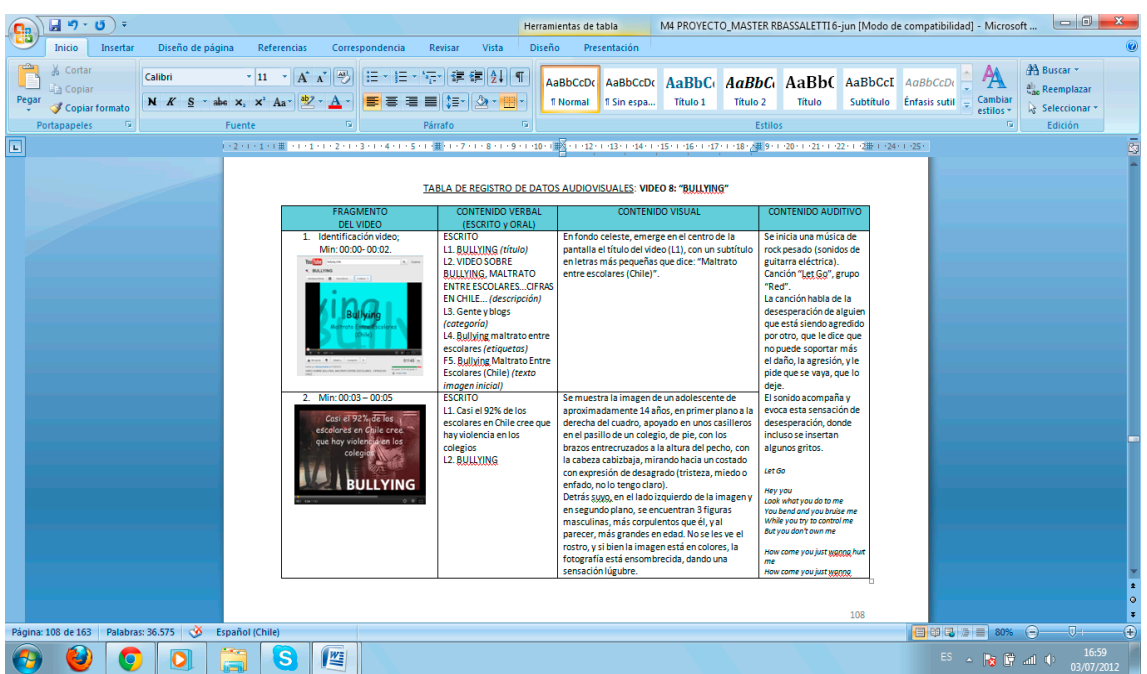


de análisis de discurso de construcción propia (véase la Tabla 2):

Se usa la letra L (de "línea") antes de la frase que contiene el contenido verbal. Así, el contenido "V7F8-L4" se refiere al ubicado en el video 7, fragmento 8, línea 4.

En el análisis de tropos y otras figuras retóricas se utilizó como texto de apoyo el "Manual de Retórica Española" de los profesores Antonio Azaustre \& Juan Casas (2006). Se elaboró un Glosario de los tropos y figuras retóricas utilizadas en el análisis.

Los resultados obtenidos del análisis del contenido verbal más aquellas descripciones del contenido audiovisual y de la identificación del video, se presentaron en primera instancia divididos por videos. Finalmente, se reunieron nuevamente tales resultados, pues el mensaje construido en el video es producto de la conjunción de todos estos elementos.

Aspectos éticos y políticos. En el presente estudio se emplearon materiales de disponibilidad pública, lo cual sitúala discusión ética en torno al uso de los resultados. En efecto, la utilización de los videos se realizó sólo con fines investigativos en relación a los discursos construidos en ellos. No obstante, cabe hacer referencia a la controversia actual en torno a las implicancias éticas de la investigación en medios virtuales, la cual principalmente se refiere a la dicotomía "público v/s privado".
Según Adolfo Estalella \& Elisenda Ardèvol (2011), desde la última década del siglo XX algunos investigadores comenzaron a interpretar que aquellas interacciones accesibles en Internet podían considerarse públicas, al ser por definición sistemas de almacenamiento, transmisión y recuperación de comentarios, por lo cual no era necesario informar ni solicitar permiso a los participantes. Por otra parte, mencionan que otros autores plantean que lo "accesible" no equivale a lo "público", y así no necesariamente interacciones a las que el investigador tiene acceso los usuarios las interpretarían como públicas, considerando "de su propiedad" el material que se publica.

Teniendo en cuenta esta discusión sobre la $e$-research (investigación en Internet), es que las decisiones éticas en este trabajo se tomaron en base a las características del espacio virtual sobre el que se trabaja. Al respecto, es posible señalar que YouTube es una plataforma presentada como un espacio para "compartir videos con personas de todo el mundo", lo cual apunta directamente a su carácter público. Pese a ello, se da la opción de limitar el acceso al material que se publique, pudiendo restringirlo sólo a algunos contactos, según "opciones de privacidad". En palabras de la empresa:

"Hemos creado YouTube para que los usuarios puedan compartir sus vídeos fácilmente

Tabla 2.

Tabla de análisis de discurso para contenidos verbales.

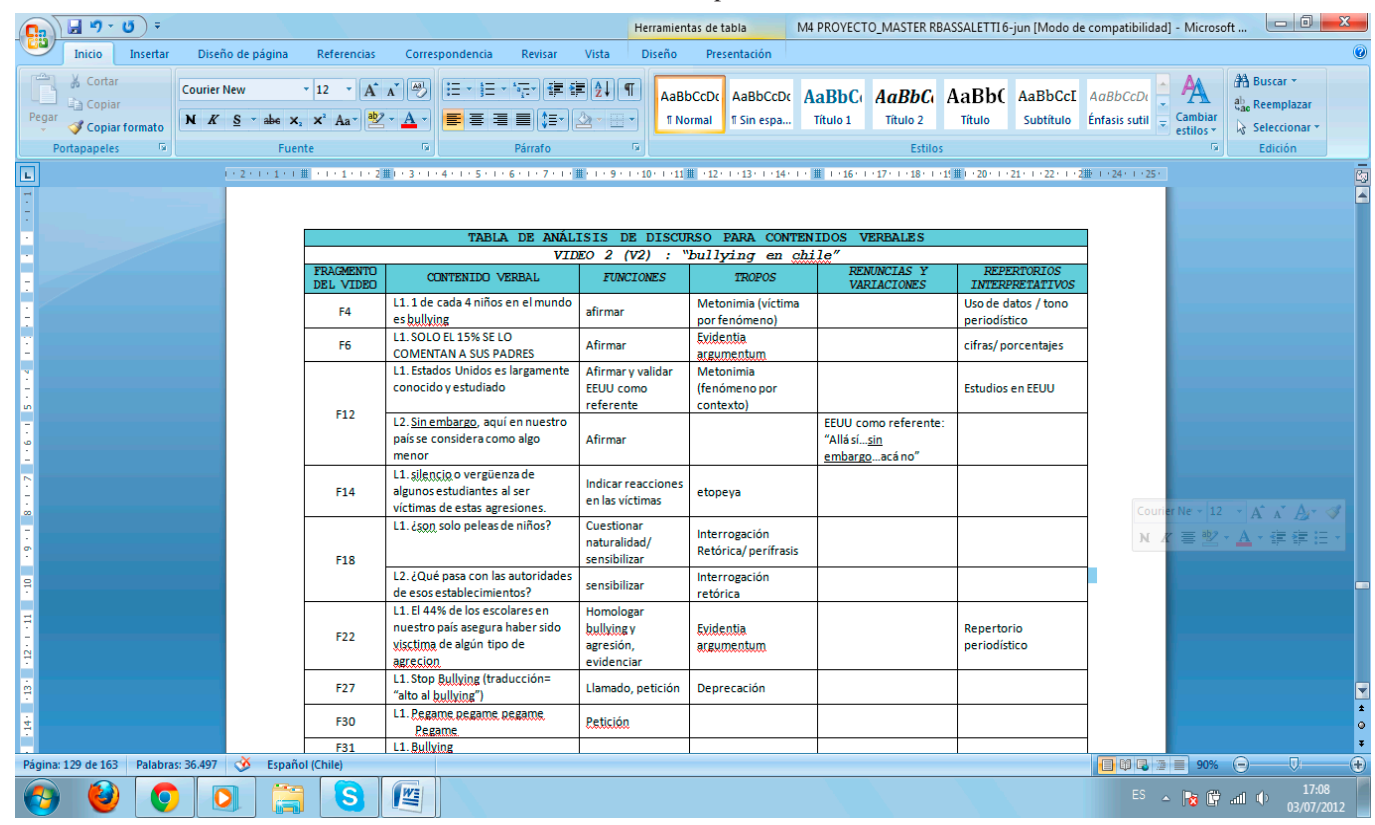


con personas de todo el mundo. Es posible que en ocasiones no quieras que todos los usuarios vean tus vídeos o accedan a tu canal y que prefieras compartir tu trabajo únicamente con un grupo reducido de amigos o de familiares". (YouTube, 2012, II 5)

Bajo estas características, en el caso de esta investigación se considera el material seleccionado de carácter público, pues los usuarios no restringen la privacidad de su material, compartiéndolo abiertamente con quien acceda a su publicación.

En cuanto a los aspectos políticos, cabe plantear este trabajo como un intento de acentuar las características propias del lugar donde se produce la investigación, haciendo presentes las variables socio-histórico-culturales a la hora de realizar producción de conocimiento científico, en este caso, sobre el fenómeno descrito como bullying.

A juicio del investigador, en diversos sectores de la sociedad chilena (la academia, el mundo político) existe una mirada constante del mundo occidental llamado "desarrollado", con la consiguiente incorporación de modelos construidos en estas sociedades tal y como son diseñados, no considerando las particularidades locales. En este sentido, se busca establecer reflexiones al respecto, planteando repercusiones de la adopción de miradas extranjeras sin la adecuación al contexto nacional.

\section{Resultados}

A partir de los datos encontrados es posible observar que el anglicismo bullying se usa de distintas formas en los videos analizados, vehiculando distintos significados asociados al término. En términos generales, se aprecian dos grandes usos de la palabra:

1. Bullying como agresión: que evidencia un uso amplio de palabra homologándola a "maltrato", y desde ahí, usándola para referirse a distintas conductas agresivas, como hacia la policía: por ejemplo, "Bullying a los $\operatorname{pacos}^{3}$ " (en título V9); a los profesores: "El fenómeno de bullying a los profesores ha llegado a Chile" (V5-F1-L2); peleas: "¿son sólo peleas de niños?” (V2-F18-L1); molestar (etiquetas V4); maltrato entre jóvenes independiente del contexto: "al que te pegaba jugando en la plaza"

\footnotetext{
"Pacos"= chilenismo coloquial para referirse a los policías o carabineros.
}

(V7-F1-L22); e incluso como enfermedad: "el bullying es una enfermedad peligrosa" (V4-F1-L5).

2. Bullying como abuso entre escolares: uso más restringido donde se le entiende dentro de una relación de poder, diferenciando entre "débiles y fuertes" o "víctimas y victimarios", cuyos protagonistas son escolares. Los significados que se relacionan a este uso implican violencia en esta ya mencionada relación asimétrica, omitiendo el contexto o los testigos como participantes de esta relación. Así, se sustituye por otros términos que marcan esta asimetría, tales como hostigamiento o acoso: "se entiende por bullying o acoso el hostigamiento y maltrato..."(V1-F2-L2);matonaje (etiquetas V3); intimidación:"los tipos de intimidación son:" (V8F9-L1);violencia escolar: "Casi un 92\% de los escolares cree que hay violencia en los colegios" (V8-F2-L1); y maltrato entre escolares: "bullying: maltrato entre escolares" (V3-F1-L5).

Cabe señalar que ambos usos del anglicismo no son excluyentes, utilizando la palabra con mayor o menor restricción.

Al hacer la revisión bibliográfica, se detecta que ninguna de las dos acepciones coincide exactamente con la definición general que propone la academia, es decir: "se caracteriza por el uso de una conducta agresiva sistemática y reiterada contra determinados niños y en una relación de desequilibrio de poder entre los agresores y sus víctimas" (Pepler, Rigby\& Smith, 2004 y Olweus, 1993; en Ortega, 2010, p.130; Garaigordobil\&Oñederra, 2010; Wolf \& Esteffan, 2008; Avilés, 2006; Sullivan, Cleary \& Sullivan, 2005). Pese a ello, entre ambas acepciones, es el uso de " $b u$ llying como abuso entre escolares" el que se acerca más a esta definición académica, excepto por la sistematicidad de la agresión y porque más que referirse a niños/ as se refiere a individuos en edad escolar, existiendo una asociación con el contexto educativo.

Al revisar la investigación chilena, donde se prefiere hablar de violencia escolar, se observa que el uso ampliado (bullying como agresión), se aleja de ella al no restringirse al ámbito de los colegios, mientras que la segunda acepción difiere en tanto implica el abuso de un individuo o grupo hacia otro niño/a, centrándose en la dicotomía victimario-víctima, no considerando otras formas de violencia en la escuela ni la comprensión de un fenómeno bullying de manera sistémica. Por otro lado, los programas de intervención y proyectos nacionales revisados, se acogen en general al uso de violencia escolar por sobre otros términos, lo cual no se condice con lo observado, en tanto el término bullying se estaría 
empleando inequívocamente junto a o en reemplazo de violencia escolar, o bien como acoso escolar, pero con explicaciones individualistas.

En cuanto al ámbito legal, la Ley sobre Violencia Escolar no habla de bullying, sin embargo, usa el concepto de acoso escolar. En este sentido, el segundo uso como abuso entre escolares es el que más se asemeja, diferenciándose en que no necesariamente implica la reiteración de la conducta agresiva.

Cabe señalar en este aspecto que se detecta una contradicción en la misma Ley, pues por una parte se entiende la violencia escolar (y el acoso escolar) como responsabilidad de la comunidad educativa en general (incluso estableciendo responsabilidades legales al respecto), pero por otro lado la propia definición que establece apunta a la dicotomía entre victimario y víctima, omitiendo el papel del resto de miembros de esa comunidad.

Finalmente, en cuanto a los medios de comunicación masivos, los investigadores señalan que "la agresión en la escuela es unifactorializada quedando definida unívocamente en una dicotomía agresor/víctima, donde priman fundamentalmente y tienen más tribuna las explicaciones psicológicas e individualistas" (Madriaza, 2007). De esta forma, bullying es entendido como "agresión", en lo cual se asemeja al uso amplio del concepto, pero circunscribiéndolo al ámbito escolar y replicando la dicotomía señalada.

Este último es el uso con más similitudes a los encontrados en la investigación, pues si bien se refiere al concepto amplio de agresión también incluye los comportamientos violentos, planteando esta dicotomía víctima-victimario (o agresor-agredido). El concepto transita así entre agresión y violencia, pudiendo confundirse con otras conductas que no necesariamente implican violencia.

El siguiente cuadro resume las similitudes y divergencias entre los usos encontrados en la revisión teórica y los dos resultantes del análisis realizado:

En cuanto a los repertorios interpretativos utilizados para la construcción de los mensajes, es posible apreciar tres articulaciones.

Un primer repertorio periodístico argumenta afirmaciones por fuentes externas y legitimadas socialmente, como la ciencia o la ley, para lo cual usa

Tabla 3.

Cuadro resumen de semejanzas y diferencias entre los usos de bullying.

\begin{tabular}{l|l}
\hline USO 1 & USO 2 \\
BULIYING COMO AGRESIÓN & BULIYING COMO ABUSO ENTRE ESCOLARES
\end{tabular}

\begin{tabular}{|c|c|c|c|}
\hline \multirow{2}{*}{$\begin{array}{l}\text { DEFINICIÓN } \\
\text { GENERAL } \\
\text { ACADÉMICA }\end{array}$} & Semejanzas & Traspasan el contexto escolar & $\begin{array}{l}\text { Implican una relación asimétrica y dicotómica } \\
\text { de abuso entre víctima/ victimario }\end{array}$ \\
\hline & Diferencias & $\begin{array}{l}\text { La definición académica implica } \\
\text { una relación asimétricay } \\
\text { dicotómica de abuso entre } \\
\text { víctima/ victimario }\end{array}$ & $\begin{array}{l}\text { No se circunscribe al ámbito escolar en el caso } \\
\text { de la definición general del mundo académico. } \\
\text { El uso } 2 \text { no implica reiteración del abuso. }\end{array}$ \\
\hline \multirow{2}{*}{$\begin{array}{l}\text { DEFINICIÓN } \\
\text { INVESTIGACIÓNE } \\
\text { INTERVENCIÓN EN } \\
\text { CHILE }\end{array}$} & Semejanzas & $\begin{array}{c}\text { Se refiere a distintos tipos de } \\
\text { agresión }\end{array}$ & $\begin{array}{c}\text { Se circunscriben al ámbito escolar y se usan } \\
\text { como violencia (abuso) }\end{array}$ \\
\hline & Diferencias & $\begin{array}{l}\text { En la investigación e } \\
\text { intervenciones se circunscribe al } \\
\text { contexto escolar }\end{array}$ & $\begin{array}{l}\text { El concepto de violencia escolar de las } \\
\text { investigaciones implica distintos tipos de } \\
\text { violencia y componentes, no sólo la relación } \\
\text { dicotómica entre victimario/víctima }\end{array}$ \\
\hline \multirow[t]{2}{*}{$\begin{array}{l}\text { LEY CHILENAY } \\
\text { POLITICAS PÚBLICAS }\end{array}$} & Semejanzas & $\begin{array}{c}\text { Ambas implican distintos tipos de } \\
\text { agresión }\end{array}$ & $\begin{array}{c}\text { Se circunscribe al ámbito escolar y se usa como } \\
\text { violencia (abuso) en una relación asimétrica y } \\
\text { dicotómica víctima-victimario }\end{array}$ \\
\hline & Diferencias & $\begin{array}{l}\text { Ley especifica relación asimétrica } \\
\text { y contexto escolar }\end{array}$ & $\begin{array}{l}\text { La ley incluye a la comunidad en la forma de } \\
\text { enfrentar la problemática, añade la reiteración } \\
\text { del acoso }\end{array}$ \\
\hline \multirow{2}{*}{$\begin{array}{l}\text { USOEN MEDIOS DE } \\
\text { COMUNICACIÓN } \\
\text { MASIVOSEN CHILE }\end{array}$} & Semejanzas & $\begin{array}{l}\text { Ambas contienen distintos tipos } \\
\text { de agresión }\end{array}$ & $\begin{array}{l}\text { Se circunscribe al ámbito escolar y se usa en } \\
\text { una dicotomía víctima-victimario }\end{array}$ \\
\hline & Diferencias & $\begin{array}{l}\text { En los medios se circunscribe al } \\
\text { contexto escolar }\end{array}$ & $\begin{array}{c}\text { No se observan diferencias sustanciales. En los } \\
\text { medios el término transita entre agresióny } \\
\text { violencia. }\end{array}$ \\
\hline
\end{tabular}


aseveraciones como "Según el diputado...", "Algunos estudios...", o bien se presentan a través de cifras y porcentajes, por ejemplo: "El 75\% de los afectados..."; apoyando las frases con imágenes de agresiones. Este tipo de repertorio se aprecia en 5 de los 9 videos analizados.

Más allá de la acepción que se utilice, al hablar de bullying se resalta en las imágenes de los videos la agresión física por sobre otras formas de violencia como la exclusión o la violencia verbal, lo que se ejemplifica especialmente en el contenido visual de los videos. La agresión física se basaría en la fuerza del victimario por sobre la víctima, la cual estaría dada -según el contenido de los videos- por mayor tamaño, mayor edad o mayor cantidad de individuos. Todos estos casos representan mayor fuerza física de los agresores, quienes al igual que las víctimas, son caracterizados, a saber como:

a. Víctima: se le caracteriza como débil, tanto física como psicológicamente, destacando su indefensión ante el agresor (V6). Se le asocian a su vez algunas consecuencias a raíz del bullying: soledad, ansiedad y desesperación (V1), pensamientos suicidas (V1, V3), suicidio (V1, V3, V4), estrés, problemas académicos, tristeza, aislamiento, sufrimiento, dolor, agotamiento (V6) y traumas (V6 y V7).

b. Victimario: se le llaman "matones", indicando que son los que ostentan la fuerza en la relación asimétrica de poder y caracterizándolos entonces como fuertes físicamente en la mayor parte de los videos y también psicológicamente en lo que se refiere a "alta autoestima" y "socialmente líder". Se señala que podría tener consecuencias a raíz del bullying, como una tendencia a la delincuencia y criminalidad.

A ambas figuras se le asocian algunos estereotipos, como "guatón ${ }^{4}$, mateo $^{5}$ o flojo" en el caso de la víctima, $\mathrm{y}$ "hombre, pandillero e inadecuado socialmente" en el caso del victimario. Llama la atención especialmente que cada uno de ellos se ejemplifican a través de imágenes relacionados con otros contextos socioculturales, especialmente con Estados Unidos.

Además de esta descripción y denuncia del bullying dada en el repertorio periodístico, es posible identificar un repertorio contra-bullying, conformado por aquellos llamados explícitos para enfrentar la problemática, los que son encontrados en 4 videos. La diferencia

\footnotetext{
4 "Guatón"= chilenismo que indica a un hombre gordo o con abdomen abultado (femenino = 'guatona').

5 "Mateo"= chilenismo que se refiere a un alumno estudioso, de buenas calificaciones.
}

cabe en las formas, ejerciéndose llamados a la denuncia, pero también al enfrentamiento directo, incluso justificando el uso de la agresión. Aquí se manifiesta una contradicción con las propuestas presentadas en las investigaciones, las intervenciones y las políticas públicas, pues se enfrenta la violencia con violencia. El argumento utilizado es la pasividad de la comunidad escolar ante las agresiones y la ineficacia de las intervenciones al respecto.

Una tercera forma contra-bullying indica el establecimiento de normas para enfrentarlo, haciendo la analogía con los signos de tránsito que señalan, por ejemplo, "zona de no bullying". Lo riesgoso desde esta perspectiva, es ubicar el bullying (como abuso o agresión) en una dimensión social en vez de moral, pues las normas implican acuerdos sociales, reglas que deberían cumplirse, lo que puede o no hacerse. Una cosa es "deber hacer" y otra "poder hacer". Así, decretar una "zona de no bullying" señala por oposición la existencia de "zonas de sí bullying", sacando al bullying de una dimensión moral en donde la convivencia se contrapone ontológicamente a cualquier acción que involucre violencia (daño, destrucción, imposición de fuerza) a otro miembro de la comunidad.

Una tercera gama de unidades lingüísticas dan cuenta de un repertorio emotivo, el cual busca generar emociones en la audiencia. Para ello se utilizan recursos a partir de experiencias de los protagonistas, particularmente en aquellos videos que muestran vivencias de víctimas de bullying. Este tipo de repertorio se observa en 5 de los 9 videos analizados.

Uno de los videos ("V9: bullying a los pacos") marca una diferencia: mientras los otros videos buscan sensibilizar al espectador con el drama del bullying, este busca provocar risas, dándole un tono humorístico a las agresiones presentes en la grabación, con lo cual queda implícita una valoración positiva del contenido del video. Así, al repertorio emotivo se le relaciona con una función de sensibilización con respecto al tema, independiente que se le otorgue una valoración negativa o positiva.

Cabe señalar que los tres repertorios se superponen en los distintos discursos encontrados. La Figura 2 sintetiza los mismos.

\section{Reflexiones finales}

A partir de este análisis se ha querido profundizar en cómo se emplea el concepto bullying en discursos chilenos relacionados con el tema. A modo de conclusión es posible señalar que las variaciones encontradas entre los 


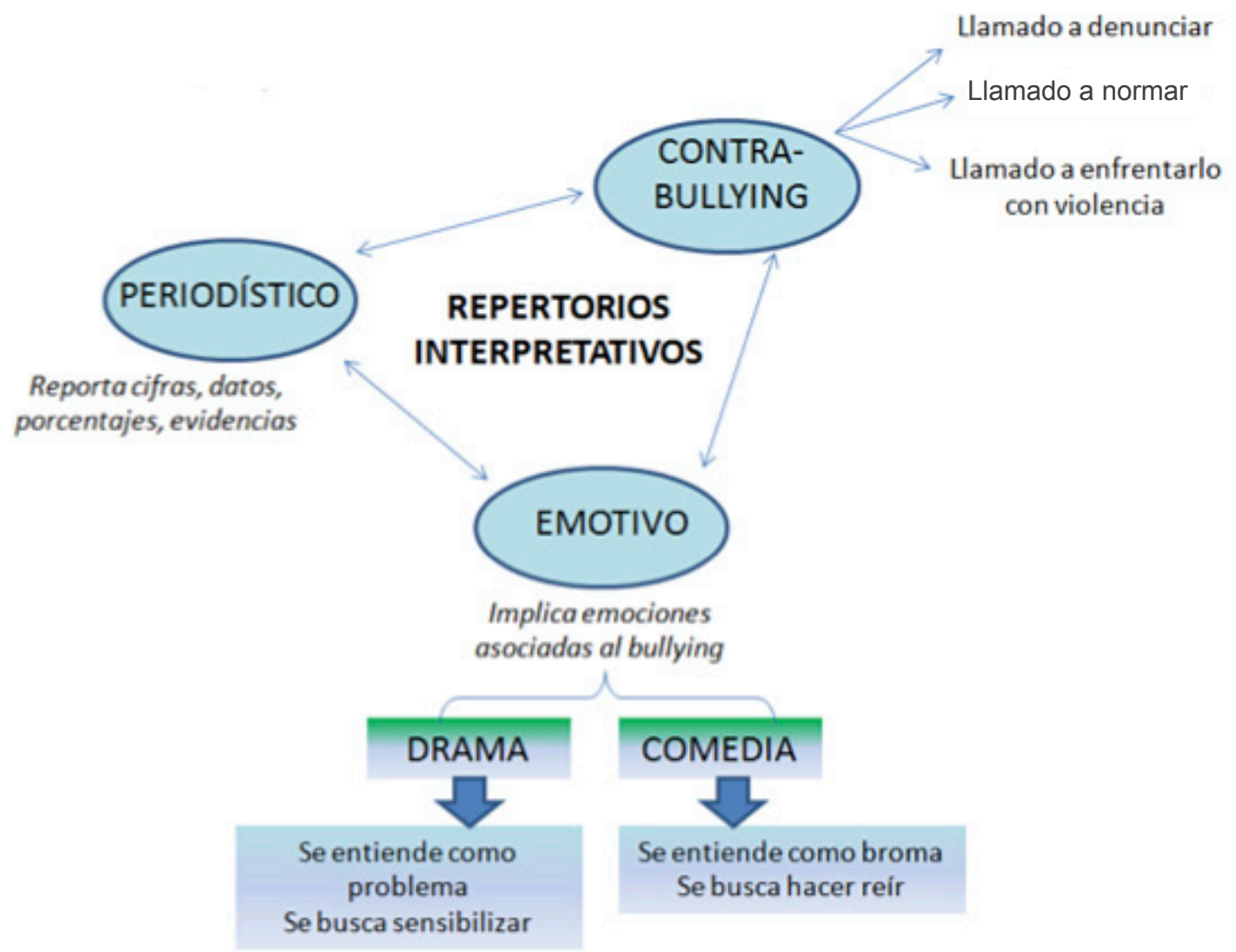

Figura 2. Repertorios interpretativos en torno al bullying.

distintos usos del anglicismo, dan cuenta del carácter dinámico del lenguaje y de un proceso de "apropiación lingüística", concepto que se plantea en esta investigación para referirse al proceso de co-construcción de significados que implica la adopción de un extranjerismo. Tal proceso contempla dos movimientos. En primer lugar una "a-propiación" del término, es decir, dejarlo "sin-lo propio", despojándolo de las características esenciales que lo conforman. Luego, al dejarlo "desprovisto" de su significado inicial, el constructo va mutando e incorporando elementos del nuevo escenario sociocultural donde se encuentra, indexándose al repertorio interpretativo de este nuevo medio social mediante vínculos con otros significados, vale decir, una "apropiación" en la acepción etimológica de esta palabra (del latín appropriāre) que quiere decir "hacer propio algo que no lo era". Se considera este punto como central, pues si por una parte el concepto se "a-propia" (se le deja "desnudo"), el término será entonces investido por los significados presentes en los repertorios de este nuevo medio social, por lo que la revisión de los usos del término, dará cuenta de los significados vehiculados por la palabra, a la vez de cómo esa sociedad se sigue construyendo (mediante los discursos elaborados).

En el caso de bullying, se observa una acepción que lo homologa a cualquier tipo de agresión, mientras otro uso más restringido se refiere a abuso entre escolares. Ambas acepciones no se corresponden linealmente con ninguna de las propuestas definidas desde el mundo académico general, pero tampoco lo hacen con los usos que se hacen en la investigación, las políticas públicas ni los medios de comunicación en Chile.

Uno de los efectos de lo anterior es que si bullying es utilizado de distintas maneras, ¿cómo se puede entender una prevalencia o incluso las denuncias por bullying? Se cuestionan entonces los estudios de prevalencia, tanto chilenos como comparaciones internacionales, si antes no se ha profundizado cómo usa la gente esta palabra. Por esta misma razón, se pone en duda la supuesta "universalidad" del fenómeno, al menos en los términos señalados por el mundo académico actual.

Por todo lo anterior, se concuerda con otros/as investigadores/as chilenos/as en relación a hablar de violencia escolar por sobre bullying, considerando la multiplicidad de formas que adopta, al menos en este 
momento. Esto es relevante porque la violencia en el mundo escolar también se entrecruza con otros tipos de agresión, que no necesariamente implican violencia: peleas, juegos rudos, dificultades de adecuación social e incluso pueden responder a problemas de gestión de aula o a comportamientos de indisciplina o disrupción propios del ámbito escolar y del desarrollo infantojuvenil, que convierte en riesgosa la etiquetación para personas en formación tanto de "víctimas" como de "victimarios" (al seguir utilizando bullying sin hacer explícito su significado y permitiendo así la consolidación de esta mirada individualista). También es complejo para los adultos de la comunidad educativa, quienes pueden orientarse a buscar "culpables" y victimizar agredidos a la hora de abordar una situación de agresión, en vez de dimensionar su carácter sistémico y promoviendo así nuevamente los valores individualistas presentes en la dicotomía señalada. Se buscan los culpables y sus víctimas, eso es lo que importa.

En Chile, el tema del bullying se trabaja en función de la convivencia escolar, y las investigaciones, intervenciones y políticas públicas se amparan bajo principios democráticos que acentúan la responsabilidad de la comunidad escolar para enfrentar cualquier tipo de violencia escolar que surja en su interior. Esto, como un intento de estimular valores colectivistas que tradicionalmente se han asignado a la sociedad chilena, al igual que a otras sociedades latinoamericanas. Pese a ello, los usos de bullying encontrados sugieren que en vez de comprender un fenómeno con esta mirada colectiva, se está asumiendo la dicotomía víctima/victimario, que por lo demás también incorpora la ley chilena al referirse al acoso escolar en términos binarios.

Así, se advierte una discrepancia entre lo que se busca oficialmente desde las políticas públicas y la influencia que recibe cada comunidad escolar desde el medio social externo, y es que cada comunidad escolar está inserta en una comunidad mayor, la sociedad chilena en su totalidad. Es aquí donde se infieren vínculos entre estos significados y las características de nuestra sociedad actual, en la cual ya se ha descrito un progresivo desarrollo de valores individualistas y una enorme desigualdad existente a nivel social, económico y educacional. En la medida que no se generen intervenciones que apunten a un desarrollo de esos valores colectivistas y de prevención de violencia comunitaria a nivel social, no se generarán cambios sustanciales en el núcleo educativo específico.

Ante lo anterior surgen algunas sugerencias. En primera instancia, es central la reflexión sobre la responsabilidad de los distintos actores sociales adultos en esta "apropiación lingüística" de términos extranjeros, en tanto están validando a su vez una realidad cuyas características no necesariamente se corresponden con la local. No obstante, como fuentes de información legitimadas socialmente (refiriéndome específicamente a la investigación científica nacional en el área, a las leyes y a los medios de comunicación masivos), favorecen aceptar la existencia de dicha realidad, con lo cual a la vez se legitiman acciones, procedimientos e intervenciones que finalmente se corresponden con las categorías establecidas. No quiere decir esto que la realidad propuesta no exista, sólo marca la relevancia de preguntarse si existe tal como proponen conceptos nacidos en otros contextos socioculturales.

Todos los videos son posteriores al año 2007. Esto coincide con lo señalado en el estado del arte, donde se plantea que el anglicismo bullying se acuña en los medios de comunicación desde el año 2006 con el suicidio de una niña en el norte del país. En este sentido, se corresponde con lo ocurrido en otros lugares del mundo, en donde el concepto se masifica a través de la prensa en torno a hechos graves de violencia asociados al contexto escolar, tomando en consideración otros tipos de violencia como la psicológica o social. En este sentido y observando la evolución de bullying como concepto y cómo se inserta en el medio nacional (desde los medios de masas), se sugiere profundizar especialmente en el papel de los medios de comunicación en este proceso de construcción de realidades y su responsabilidad a la hora de transmitir información y elaborar "verdades".

En otras proyecciones de este trabajo se motiva la investigación sobre significados relacionados con el género o la clase social. Esto porque a raíz de algunos resultados podría inferirse que existe una asociación del término con colegios más deprivados económicamente, como comunidades más afectadas por la violencia, mientras que se vincula el género masculino más frecuentemente con la agresión. Ninguno de estos resultados es concluyente, y para ello se motiva la utilización de metodologías que permitan profundizar en los significados particulares de estudiantes, docentes, padres y madres de la comunidad educativa.

Para finalizar, llama la atención el guiño frecuente en los distintos usos encontrados a modelos importados desde "el mundo desarrollado" especialmente de Estados Unidos. En un mundo globalizado es previsible que se intercambien productos, ideas, conceptos; además, debe considerarse que ese intercambio conlleva también lógicas que se ponen en diálogo con aquellas pertenecientes al repertorio local. Cabe sin embargo 
reflexionar sobre la hegemonía de la "industria cultural occidental", que habla de un intercambio desigual o al menos no necesariamente bidireccional. Hoy en Chile se habla de bullying, de shopping center, de malls, de lockers en vez de casilleros. ¿Será sólo una cuestión lingüística si cada concepto moviliza significados, promoviendo acciones y ciertas relaciones?

Por ello, la reflexión debe girar en torno a cómo queremos construir nuestra sociedad y qué miradas extranjeras se condicen con el contexto local. El tema es, a juicio del investigador, qué queremos "apropiarnos" como sociedad... en el sentido de "hacer propio".

\section{Referencias}

Ardèvol, E. \& San Cornelio, G. (2007). Si quieres vernos en acción: YouTube. Prácticas mediáticas y autoproducción en Internet. Revista Chilena de Antropología Visual, 10, pp. 1-29.

Avilés, J.M. (2006). Bullying: el maltrato entre iguales. Agresores, víctimas y testigos en la escuela. Salamanca: Amarú.

Azaustre, A. \& Casas, J. (2009) Manual de Retórica Española. Barcelona: Ariel

Borges, J. L. (1998). Obra poética, 1923-1985. Buenos Aires: EMECÉ Editores.

Del Rey, R., Genevat, R. \& Ortega, R. (2002). Etiquetas verbales en el vocabulario de docentes, padres y madres para nominar el fenómeno bullying. Revista Electrónica Interuniversitaria de Formación del Profesorado, 5(4). Recuperado en: http://www.aufop. com/aufop/uploaded_files/articulos/1227711372.pdf

Estalella, A. \& Ardévol, E. (2011). E-research: desafíos y oportunidades para las ciencias sociales. Convergencia, 18(55), 87-111.
Garaigordobil, M. \& Oñederra, J.A. (2010). La violencia entre iguales: revisión teórica y estrategias de intervención. Madrid: Pirámide.

Garay, A., Iñíguez, L. \& Martínez, L. M. (2005). La perspectiva discursiva en Psicología Social. Subjetividad y Procesos Cognitivos, 7, 105-130.

Geertz, C. (1992). La interpretación de las culturas. Barcelona: Gedisa.

Gergen, K. \& Gergen, M. (2011). Reflexiones sobre la construcción social. Barcelona: Paidós

Gordo, Á. \& Linaza, J. L. (1996). Psicologías, discursos y poder $(P D P)$. Madrid: Visor.

Ibañez, T. (2001). Psicología social construccionista. Guadalajara: Universidad de Guadalajara.

Lecannelier, F. (2007). Bullying, violencia escolar: ¿qué es y cómo intervenir? Santiago, Chile. Recuperado de: http://www.cplasalle. cl/Bullying-Lecannelier-2007.pdf

Madriaza, P. (2007). Violencia Escolar en Chile. En Guajardo García, C. [Ed.] (2008). Seguridad y prevención: La situación en Argentina, Chile y Uruguay. Recuperado de:http://derecho.uahurtado. $\mathrm{cl} / \mathrm{psu} /$ documentos/publicaciones/Seguridad_y_Prevencion.pdf

MINEDUC (2011). Ley 20.536 Sobre Violencia Escolar en Bases de Datos Diario Oficial. Recuperado de: http://www.anfitrion.cl/ actualidad/20ulle/20536.html

Ortega, R. [coord.] (2010). Agresividad injustificada, bullying y violencia escolar. Madrid: Alianza.

Potter, J. \& Wetherell, M. (1987). Discourse \& Social Psychology. London: Sage.

Sprague, J., Tijmes, C. \& Varela, J. (2009). Paz Educa: Programa de prevención de la violencia escolar. Recuperado de: http://www. pazciudadana.cl/docs/pub_20100218170450.pdf

Sullivan, K., Cleary, M. \& Sullivan, G. (2005). Bullying en la enseñanza secundaria. Barcelona: Ceac.

Wolf, C. \& Esteffan, K. (2008).Bullying: una mirada desde la Salud Pública. Revista Chilena de Salud Pública, 12(3), 181-187.

YouTube (2012). Privacidad en YouTube. Recuperado en: http://www. youtube.com/static?hl=es-MX\&template=privacy_at_youtube 